Communications in Physics, Vol. 30, No. 4 (2020), pp. 383-390

DOI:10.15625/0868-3166/30/4/15447

\title{
DEVELOPMENT OF NOVEL 3D PRINTABLE GRAPHENE-BASED COMPOSITE TOWARDS FABRICATION OF THIN FILM ELECTRODE MATERIAL*
}

\author{
LE T. M. HANH ${ }^{1}$, DO T. THUY ${ }^{1,2}$, HOANG T. DUNG ${ }^{1}$, DOAN T. TUNG ${ }^{1}$, VU X. MINH ${ }^{1}$, \\ PHAM T. LAN ${ }^{1}$, LE T. LU ${ }^{1,2}$, TRAN D. LAM ${ }^{1,2}$ AND NGUYEN T. DUNG ${ }^{1,2 \dagger}$ \\ ${ }^{1}$ Institute for Tropical Technology, Vietnam Academy of Science and Technology, \\ 18 Hoang Quoc Viet, Cau Giay, Hanoi, Vietnam \\ ${ }^{2}$ Graduate University of Science and Technology, Vietnam Academy of Science and Technology, \\ 18 Hoang Quoc Viet, Cau Giay, Hanoi, Vietnam \\ ${ }^{\dagger} E$-mail: ndung@itt.vast.vn \\ Received 01 September 2020
}

Accepted for publication 13 November 2020

Published 25 November 2020

\begin{abstract}
Graphene/polymer composite thin film electrodes have many important applications, but the fabrication of these electrodes is often difficult because of poor processability of graphene. This paper presents the primary results on using $3 D$ printing technique for thin film electrode preparation from graphene-based composite ink. The printing ink was synthesized from graphene oxide (GO), polyvinyl alcohol (PVA) as a binder and stabilizer, and ascorbic acid (AA) as a reducing agent. The measured zeta potential value showed that PVA can make GO ink more stable, the absolute value of zeta potential increased from $10.1 \mathrm{mV}$ (without PVA) to $31.4 \mathrm{mV}$ (with $12 \mathrm{wt} . \%$ $P V A$ ). The thin film electrodes can be easily printed using GO/PVA/AA composite ink, and obtained voltammograms recorded on the surface of these electrodes in $5 \mathrm{mM} \mathrm{K}_{3}\left[\mathrm{Fe}(\mathrm{CN})_{6}\right] / \mathrm{K}_{4}\left[\mathrm{Fe}(\mathrm{CN})_{6}\right]$ solution clearly indicated the $G O$ reduction by $A A$. The best electrochemical properties of printed electrodes were founded in the case of composite ink with wt/wt ratio GO:PVA:AA = 80:12:8. The cyclic voltammetric results demonstrated the linear dependence of the anodic and cathodic signals of redox couple $\left[\mathrm{Fe}(\mathrm{CN})_{6}\right]^{4-} / \mathrm{K}_{3}\left[\mathrm{Fe}(\mathrm{CN})_{6}\right]^{3-}$ with the square root of scan rate, indicating a reversible redox reaction on the electrode surface. The thin films printed from GO/PVA/AA composite ink can be used as electrode material for diverse applications in electrochemistry.
\end{abstract}

Keywords: 3D printable ink, graphene composite, polyvinyl alcohol, ascorbic acid, electrode material.

Classification numbers: 81.05.ue; 82.45.Fk; 82.45.Mp.

* This paper is dedicated to the $40^{\text {th }}$ anniversary of Institute for Tropical Technology

C2020 Vietnam Academy of Science and Technology 


\section{INTRODUCTION}

Graphene is considered a miracle materials of the 21 st century due to its great electronic mobility, excellent electrical and thermal conductivity, with a large theoretical specific surface area of $2630 \mathrm{~m}^{2} \cdot \mathrm{g}^{-1}$. Hence graphene has attracted much attention in many different fields, from basic research to applied research [1]. Graphene has been widely explored in electrochemistry, it is reported that graphene-based electrode materials have potential applications in nanoelectronics, field effect transistor, solar cell, light emitting diodes, sensor, energy storage, etc. [2-5]. Graphene electrodes currently can be divided into 3 types: pristine graphene, chemical vapor deposition (CVD) graphene and composite graphene electrodes, in which graphene/polymer composite material is most noticeable due to significant advantages of easy processing and low cost [6]. Graphene/polymer composite thin film electrodes have many important applications and they are usually synthesized by solution method using spin-coating, drop casting, Langmuir-Blodgett (LB), self-assembly techniques [6,7]. In recent years, 3D printing technology has strongly developed that makes the fabrication of thin film electrode much more easy, more precise and more rapid [8-10].

The term 3D printing was born in 1980s and it has developed significantly in recent years, along with the strong growing of informative and automotive technologies. To date, this technology plays an important role in many applications in various fields: custom art and design, architecture, aerospace, energy, medicine, etc. A 3D printer can copy and create objects directly from the model on a computer, with a super precision. Almost 3D printing graphene-based inks started out from graphene oxide (GO) form due to its good water-dispersibility and production possibility on an industrial scale. After printing, GO will be reduced to rGO by different physical or chemical methods [11-13]. However, pure GO solutions have a limited rheological property and some additives have been studied to resolve this problem, for example silica powder [14], a branched copolymer surfactant [15], poly(acrylic acid) [16]. Several recent publications demonstrated very interesting results on the use of combination of GO and polyvinyl alcohol (PVA) for the electrode preparation. The resulted GO/PVA electrode materials have been reported to exhibit the excellent mechanical properties [17,18]. PVA is one of the hydrophilic polymer and it can act as a matrix for other materials. PVA is well known for its high water solubility, good flexibility, excellent film-forming behavior and mechanical properties.

In this work, GO was synthesized via chemical oxidation route from commercial graphite and used for the preparation of 3D printing ink. PVA was used as a dispersant to improve the rheological property and stability of the ink, and ascorbic acid (AA) was also used for GO reduction. The electrochemical properties of prepared 3D-printed GO/PVA/AA thin composite films have been characterized by cyclic voltammetry method with potassium ferricynaide/ferrocyanide redox couple.

\section{EXPERIMENT}

\section{II.1. Preparation and characterization of graphene-based ink}

In this work, 3D printing ink was prepared from GO, PVA (as a binder), and AA (as a reducing agent). GO was synthesized from graphite powder by chemical oxidation via the improved Hummer's method reported in 2010 by Marcano et al. [19]. Briefly, $1.0 \mathrm{~g}$ graphite powder was added into $100 \mathrm{~mL}$ of mixture of concentrated acid H2SO4 and H3PO4 (90 ml and $10 \mathrm{ml})$ under 
vigorous stirring. Then $6.0 \mathrm{~g} \mathrm{KMnO}_{4}$ was added slowly. The oxidation reaction carried out at $50 \mathrm{oC}$ with continuous stirring during $12 \mathrm{~h}$. After that, $100 \mathrm{~mL}$ water with $\mathrm{H}_{2} \mathrm{O}_{2}(30 \%)$ was added to the mixture, the color of solution turned from brown to yellow. The precipitate was centrifuged off and washed several time with distilled water and then sonicated for $1 \mathrm{~h}$ to form GO gel.

In our study, the binder PVA acts also as dispersant and stabilizer for GO ink. Aqueous solution PVA with different amount was added into GO gel, thoroughly sonicated to form GO/PVA composite ink. The stability of the samples has been investigated by measuring the zeta potential at room temperature $\left(25^{\circ} \mathrm{C}\right)$ on a Malvern Zetasizer Nano ZS. For the purpose of direct printing the electrode material, AA was also added into the GO/PVA composite inks. AA can act here as reducing agent which converts non-conductive GO to conductive reduced GO [20].

\section{II.2. 3D direct writing fabrication electrode materials}

In present work, thin film electrodes were fabricated using direct ink writing method on the $3 \mathrm{D}$ printer (Fig. 1) as described in our previous papers [9,10]. The composite ink was loaded into a $10 \mathrm{~cm} 3$ syringe and extruded from a $0.3 \mathrm{~mm}$ diameter nozzle directly onto a graphite paper, which was placed on a heating aluminum table of the printer, to form written patterns with dimension $10 \mathrm{~mm} \times 20 \mathrm{~mm}$. In this research, the electrode samples were designed using Solidworks software, and the printing parameters were set up as follows: printing speed is $2 \mathrm{~mm} . \mathrm{s}^{-1}$; thickness of each layer is $0.2 \mathrm{~mm}$; width of print line is $0.25 \mathrm{~mm}$; and the temperature of the sample table is $80^{\circ} \mathrm{C}$. After formation, the electrodes were dried at $100^{\circ} \mathrm{C}$ for 30 minutes in an oven.
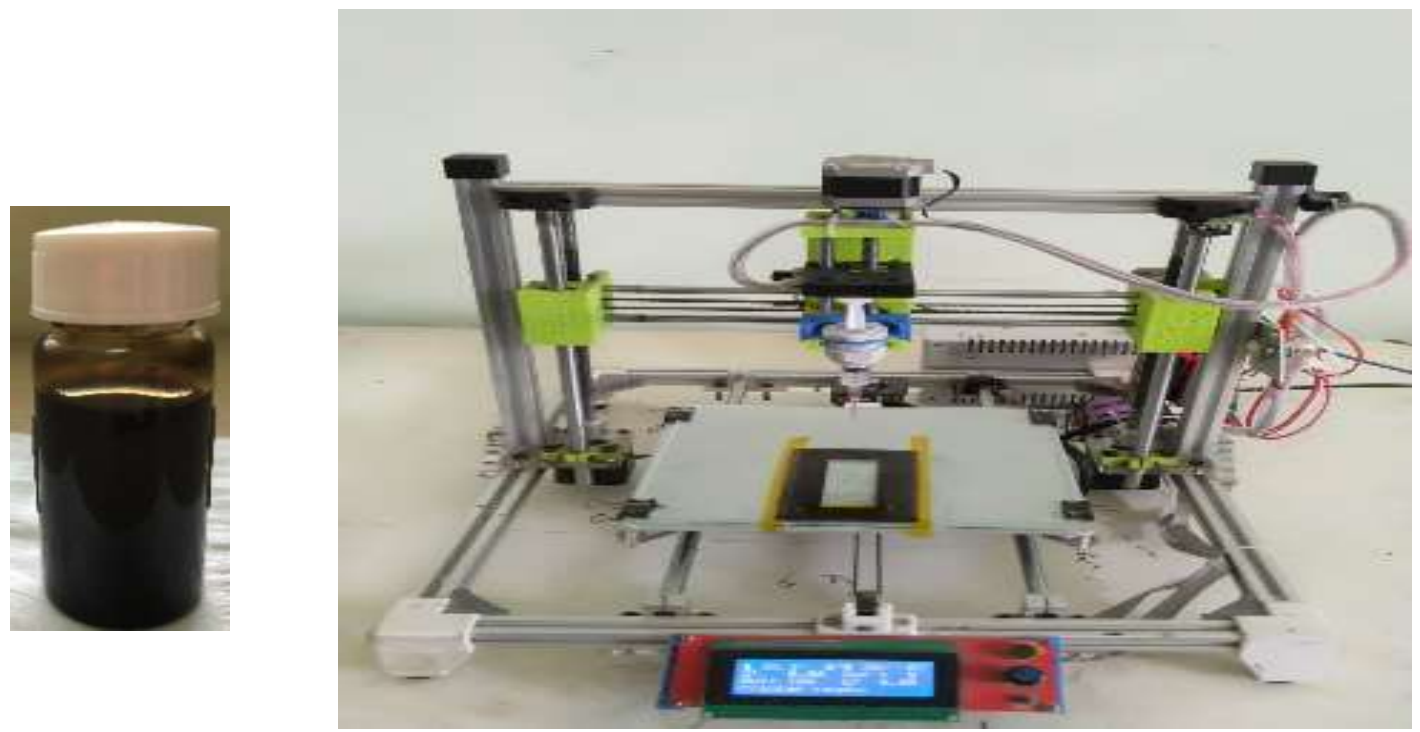

Fig. 1. GO/PVA water ink (left) and 3D printer (right).

Electrochemical properties of prepared electrodes were studied by cyclic voltammetric (CV) method in $5 \mathrm{mM} \mathrm{K} 3\left[\mathrm{Fe}(\mathrm{CN})_{6}\right] / \mathrm{K}_{4}\left[\mathrm{Fe}(\mathrm{CN})_{6}\right]$ (1:1) redox system. CV experiments were performed with a multichannel potentiostat/galvanostat (Biologic VSP-300), using three cell electrode system in which graphene-based composite film printed on graphite is taken as working 
electrode (WE), while saturated calomel electrode (SCE) and platinum grid acted as reference and counter electrode respectively. All CV measurements are performed at room temperature $\left(\sim 25^{\circ} \mathrm{C}\right)$.

\section{RESULTS AND DISCUSSION}

\section{III.1. Zeta potential measurement}

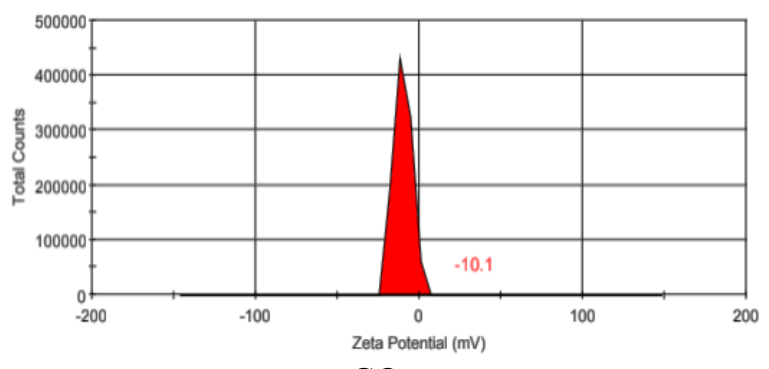

$\mathrm{GO}$

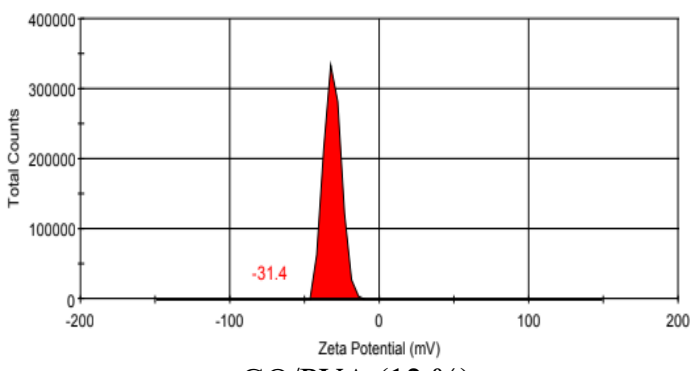

GO/PVA $(12 \%)$

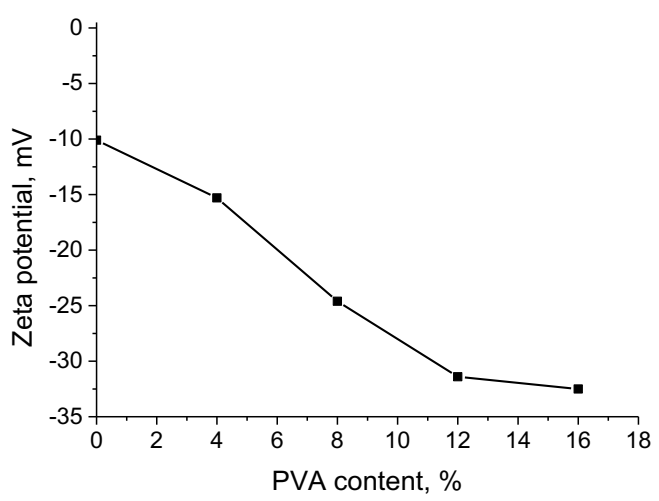

Fig. 2. Zeta potential values of GO and GO/PVA composite suspension with various PVA content.

The stability of printing ink is a very important character and it requires high dispersion force between the colloidal particles in the ink solution. The surface electrical behavior of colloidal particles can be identified by zeta potential value and it serves as an indication of dispersion stability of the ink. In present work, zeta potential parameter of prepared GO and GO/PVA ink, while PVA content varied from 4 to $16 \%$ (w/w), has been measured. It can be observed in Fig. 2 that addition of PVA has a significant influence on zeta potential of GO colloidal particles. In the case of GO suspension whithout PVA, zeta potential exhibits a relatively low value, $-10.1 \mathrm{mV}$. This indicates the weaker repulsive force among interparticles, and consequently the GO suspension is not enough stable. The absolute value of zeta potential increased significaltly by addition of PVA into the GO ink solution. In the case of $12 \%$ PVA content, zeta potential obtained $-31.4 \mathrm{mV}$, colloidal particles have enough electrostatic repulsion and the suspension can be stably well-dispersed. 


\section{III.2. Electrochemical properties of printed electrode}

\section{Influence of ascorbic acid content}

Cyclic voltammetry $(\mathrm{CV})$ is a powerful technique used to investigate the electrochemical properties of various electrodes. In present work AA was used for GO reduction, in order to rise the conductivity of printed GO/PVA composite film. The voltammetric performances of as-prepared electrode with and without $\mathrm{AA}$ have been compared using $\left[\mathrm{Fe}(\mathrm{CN})_{6}\right]^{4-} /\left[\mathrm{Fe}(\mathrm{CN})_{6}\right]^{3-}$ as a model redox system. Fig. 3 presents the cyclic voltammograms of $5.0 \mathrm{mmol} . \mathrm{L}^{-1}$ $\mathrm{K}_{4}\left[\mathrm{Fe}(\mathrm{CN})_{6}\right] / \mathrm{K}_{3}\left[\mathrm{Fe}(\mathrm{CN})_{6}\right]$ recorded on electrodes printed from mixtures: GO + 12\% PVA (GO/PVA 12$) ; \mathrm{GO}+12 \% \mathrm{PVA}+4 \% \mathrm{AA}(\mathrm{GO} / \mathrm{PVA} 12 / \mathrm{AA} 4) ; \mathrm{GO}+12 \% \mathrm{PVA}+$ 8\% AA (GO/PVA12/AA 8$) ; \mathrm{GO}+12 \%$ PVA + 12\% AA (GO/PVA12/AA12).

As can be seen from Fig. 3, in the case of GO/PVA12 film (without AA), a pair of redox peak observed very weak (curve a). With presence of AA in the film, the obtained CV curves exhibited well-defined redox couples, indicating the reduction of GO did take place. It can be also observed that the peak current increased with increasing AA content until 8\%. In the case of $12 \%$ AA the peak current lightly decreased (curve d), because probably of lower content of reduced GO in the printed composite film.

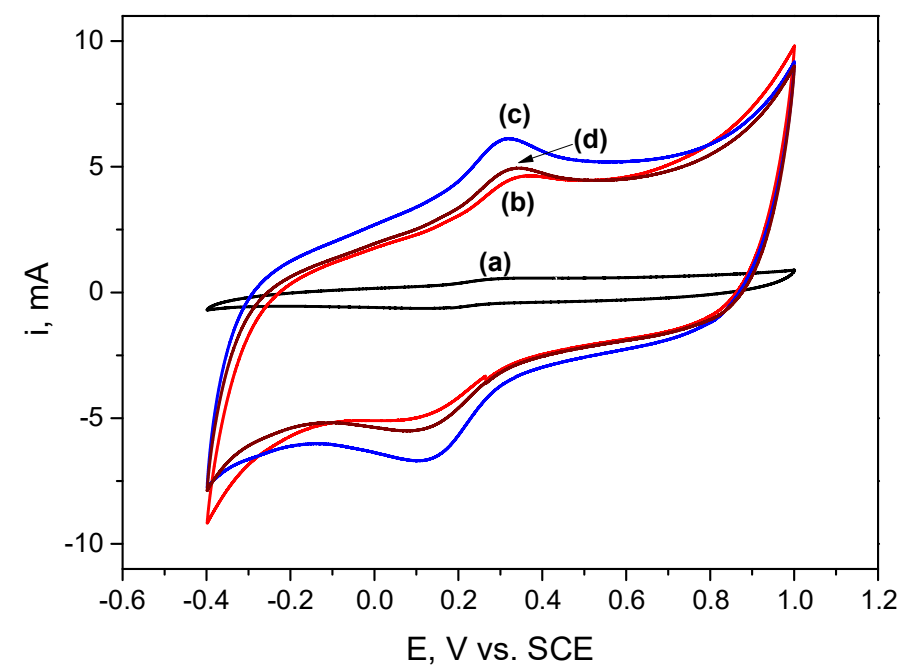

Fig. 3. Cyclic voltammogram recorded in 5 mmol. $\mathrm{L}^{-1} \mathrm{~K}_{4}\left[\mathrm{Fe}(\mathrm{CN})_{6}\right] / \mathrm{K}_{3}\left[\mathrm{Fe}(\mathrm{CN})_{6}\right]$ system at $50 \mathrm{mV} . \mathrm{s}^{-1}$ of composite films: (a) GO/PVA12; (b) GO/PVA12/AA4; (c) GO/PVA12/AA8; (d) GO/PVA12/AA12.

From the recorded $\mathrm{CV}$ curves, the peak-to-peak separation $(\Delta E p)$ of cathodic and anodic signals of model redox system could be also determined. The lowest value $\Delta E p(0.21 \mathrm{~V})$ obtained in the case of $8 \% \mathrm{AA}$, which could be ascribed to the faster electron transfer kinetics on this electrode [21]. The $\Delta E p$ value determined evidently higher, 0.32 and $0.30 \mathrm{~V}$, for the AA content of 4 and $12 \%$. The AA content of $8 \%$ (so the ratio GO:AA $=80: 8$ ) was chosen for the further investigation. 


\section{Influence of polyvinyl alcohol content}

The influence of PVA content on the electrochemical properties of printed composite thin film electrode has been also studied. Fig. 4 presents the voltammograms recorded on the GO/PVA/AA electrodes with PVA content varied from 4 to 16

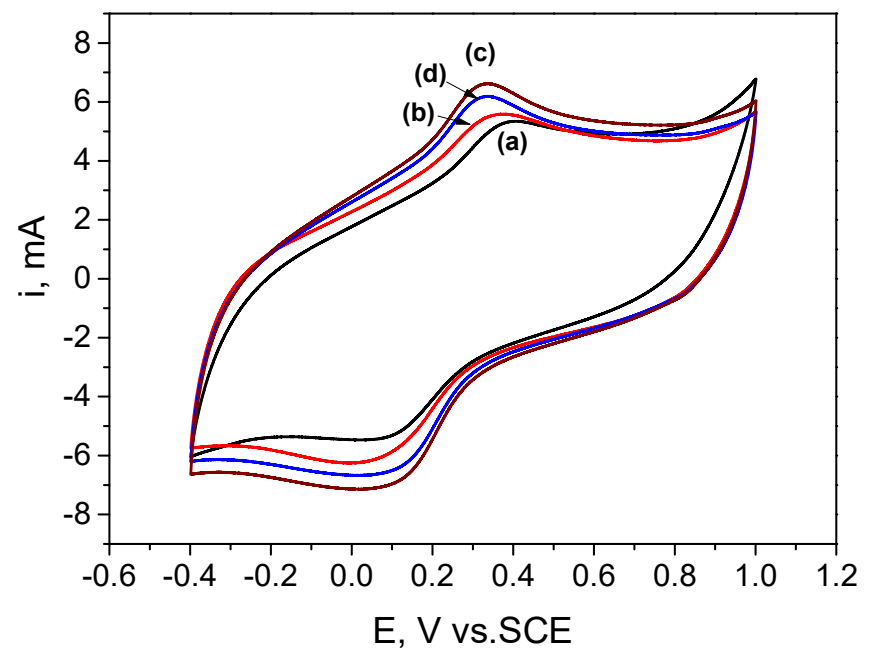

Fig. 4. Cyclic voltammograms recorded $5 \mathrm{mmol} \mathrm{L-1} \mathrm{K} 4[\mathrm{Fe}(\mathrm{CN}) 6] / \mathrm{K} 3[\mathrm{Fe}(\mathrm{CN}) 6]$ system at $50 \mathrm{mV} . \mathrm{s}-1$ of composite films printed from mixtures of GO with AA (GO:AA=80:8) and different PVA content: $4 \%$ (a); $8 \%$ (b); $12 \%$ (c); $16 \%$ (d).

As can be seen in Fig. 4, the magnitude of redox couple $\left[\mathrm{Fe}(\mathrm{CN})_{6}\right]^{4-} /\left[\mathrm{Fe}(\mathrm{CN})_{6}\right]_{3-}$ increased with increasing of PVA content from 4 to $12 \%$, but it lightly decreased in the case of $16 \%$ PVA. PVA adding to the GO ink could improve the dispersion degree of GO particles that makes the printed films with higher quality. This result is well according with the measured zeta potentials of GO/PVA composite ink, zeta potential increased with increasing PVA content. However, in the case of larger amount of PVA, $16 \% \mathrm{w} / \mathrm{w}$, the peak current in voltammogram observed lower than other samples, that is because probably of lower reduced GO content in the printed composite film. The weight ratio GO:AA:PVA $=80: 12: 8$ has been found the best composition of the printing ink for the fabrication of thin film electrode material.

\section{Influence of scan rate}

The scan rate effect on anodic and cathodic signals (ipa and ipc) of redox couple $\left[\mathrm{Fe}(\mathrm{CN})_{6}\right]^{4-} / \mathrm{K}_{3}\left[\mathrm{Fe}(\mathrm{CN})_{6}\right]^{3-}$ was also investigated on electrode printed from optimized composite ink. The obtained cyclic voltammograms, as shown in Fig. 5, demonstrate that the peak current for both anodic and cathodic peaks increases when scan rate increases from 10 to $150 \mathrm{mV} \cdot \mathrm{s}^{-1}$.

From the obtained CV curves in Fig. 5, the relation between redox peak current and square root of scan rate can be established and presented in Fig. 6. The observed linear relationship between $\mathrm{i}_{p a}$ and $\mathrm{i}_{p c}$ and $v^{1 / 2}$ indicates a reversible redox reaction on the electrode surface. Whole electrochemical process is diffusion based, that was confirmed by the available literature [22]. 


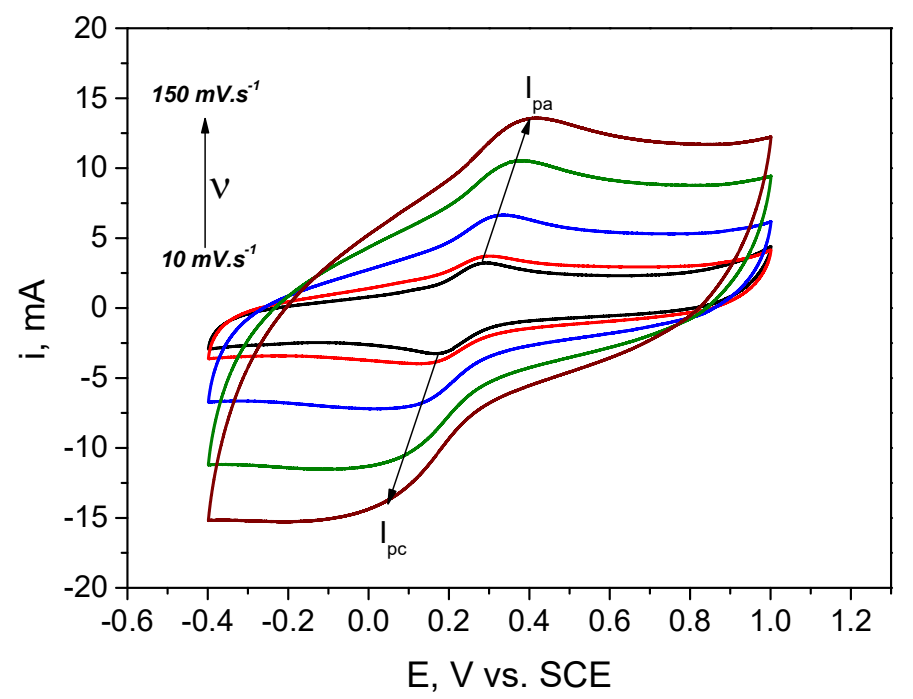

Fig. 5. Cyclic voltammograms recorded in $5 \mathrm{mM} \mathrm{K} 3[\mathrm{Fe}(\mathrm{CN}) 6] / \mathrm{K} 4[\mathrm{Fe}(\mathrm{CN}) 6]$ system at different scan rate of 10, 20, 50, 100, $150 \mathrm{mV} . \mathrm{s}-1$ on composite films GO/PVA12/AA8.

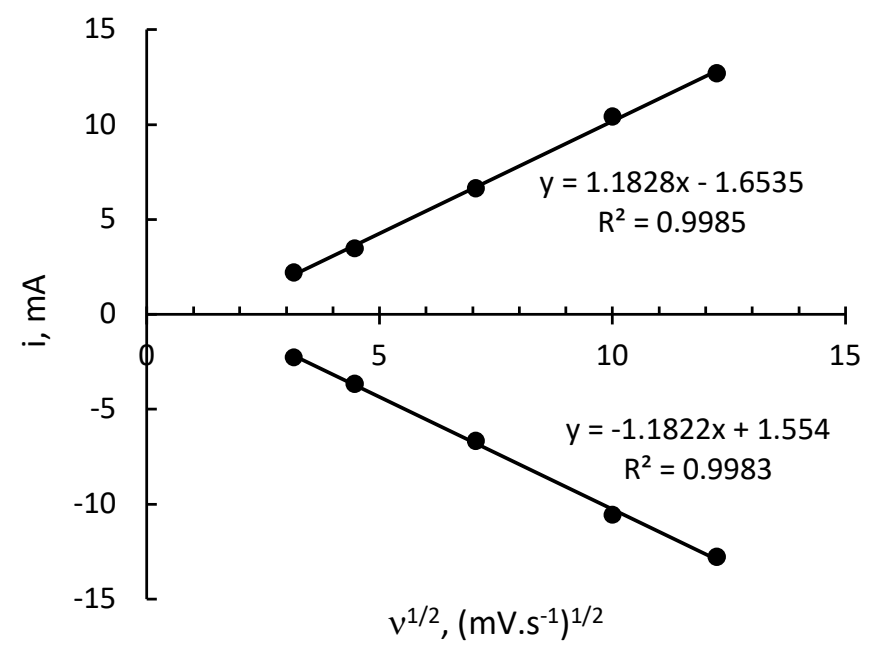

Fig. 6. The dependence of peak anodic and cathodic currents on square root scan rate $\left(v^{1 / 2}\right)$.

\section{CONCLUSIONS}

In this work, graphene-based ink was prepared from graphene oxide, polyvinyl alcohol and ascorbic acid. GO gel was synthesized via chemical oxidation of graphite, using the modified Hummer's method. The stability of GO ink has been improved by PVA addition that was indicated by zeta potential measurements. With $12 \mathrm{wt} \%$ PVA, absolute zeta potential value of colloid GO particles increased from $10.1 \mathrm{mV}$ to $31.4 \mathrm{mV}$. 
The thin film electrodes have been fabricated easily by direct writing on a 3D printer using prepared graphene-based composite ink. GO has been reduced by ascorbic acid that can be shown clearly on the voltammograms in $5 \mathrm{mM} \mathrm{K}_{3}\left[\mathrm{Fe}(\mathrm{CN})_{6}\right] / \mathrm{K}_{4}\left[\mathrm{Fe}(\mathrm{CN})_{6}\right]$ solution. PVA and AA contents have been optimized, GO:PVA:AA $=80: 12: 8(\mathrm{wt} / \mathrm{wt})$, in order to obtain the best electrochemical properties of the composite thin film electrode. The cyclic voltammetric results demonstrate also the linear relationship between anodic and cathodic signals of redox couple $\left[\mathrm{Fe}(\mathrm{CN})_{6}\right]^{4-} / \mathrm{K}_{3}\left[\mathrm{Fe}(\mathrm{CN})_{6}\right]^{3-}$ and square root of scan rate that indicates well a reversible redox reaction on the electrode surface. The thin film printed from GO/PVA/AA composite ink can be used as electrode materials for diverse applications in electrochemistry.

\section{REFERENCES}

[1] Wongbong Choi and Jo-won Lee, Graphene: synthesis and applications, CRC Press, 2011.

[2] M. Pumera, A. Ambrosi, A. Bonanni, E. L. K. Chng and H. I. Poh, Trends Analyst. Chem. 29 (2010) 954.

[3] Maher F. El-Kady, Richard B. Kaner, Nature Communications 4 (2013) 1475.

[4] M. Y. Yen, C. K. Hsieh, C. C. Teng, M. C. Hsiao, P. I. Liu, C. C. M. Ma, M. C. Tsai, C. H. Tsai, Y. R. Lin and T. Y. Chou , RSC Adv. 2 (2012) 2725

[5] Cao T. Thanh, Nguyen H. Binh, Nguyen V. Tu, Vu T. Thu, M. Bayle, M. Paillet, J. L. Sauvajol, Phan B. Thang, Tran D. Lam and Phan N. Minh, Sens. Actuators B Chem. 260 (2018) 78.

[6] Shannon M. Notley, Drew R. Evans, Adv. Colloid Interface Sci. 209 (2014) 196.

[7] T. Dung Nguyen, T. T. Huyen Dang, Hoang Thai, L. Huy Nguyen, D. Lam Tran, B. Piro and M. C. Pham, Electroanalysis 28 (2016) 1907.

[8] F. Zhou, S. Han, Q. Qian and Y. Zhu, Chem. Phys. Lett. 728 (2019) 6.

[9] Hoang T. Dung, Ngo T. Dung, Trinh Q. Dung, Doan T. Tung, Nguyen T. Yen, Le T. T. Tam, Tran V. Thu, Phan N. Hong and Le T. Lu, Vietnam J. Sci. Tech. 56 (2018) 574.

[10] Doan T. Tung, Le T.T Tam, Hoang T. Dung, Ngo T. Dung, Hoang T. Ha, Nguyen T. Dung, Thai Hoang, Tran D. Lam, Dang T. Chien, Phan N. Hong, Phan N. Minh, Nguyen V. Quynh and Le T. Lu, J. Electron. Mater. 49 (2020) 4671.

[11] F. Zhang, M. Wei, V.V. Viswanathan, B. Swart, Y. Shao, Nano Energy 40 (2017) 418.

[12] V. Dua, S. P. Surwade, S. Ammu, S. R. Agnihotra, S. Jain, K. E. Roberts, S. Park, R. S. Ruoff and S. K. Manohar, Angewandte Chemie International Edition 122 (2010) 2154.

[13] L. Baptista-Pires, A. Escosura-Muniz, M. Balsells, J. C. Zuaznabar-Gardona and A. Merkoci, Electrochem. Commun. 98 (2019) 6.

[14] C. Zhu, T. Liu, F. Qian, T. Y. Han, E. B. Duoss, J. D. Kuntz, C. M. Spadaccini, M. A. Worsley, Y. Li, Nano Lett. 6 (2016) 3448.

[15] E. García-Tuñon, S. Barg, J. Franco, R. Bell, S. Eslava, E. D’Elia, F. Guitian, E. Saiz, Adv. Mate. 27 (2015) 1688.

[16] Q. Ran, S. Wu and J. Chen, Polym. Plast. Technol. Eng. 46 (2007) 1117.

[17] X. Zhao, Q. Zhang, D. Chen and P. Lu, Macromolecules 43 (2010) 2357.

[18] P.B. Pawar, S. Shukla and S. Saxena, J. Power Sources 321 (2016) 102.

[19] D. C. Marcano, D. V. Kosynkin, J. M. Berlin, A. Sinitskii, Z. Sun, A. Slesarev, L. B. Alemany, W. Lu and J. M. Tour, ACS Nano 4 (2010) 4806.

[20] J. Zhang, H. Yang, G. Shen, P. Cheng, J. Zhang and S. Guo, Chem. Commun. 46 (2010) 1112.

[21] I. Svancara, K. Kalcher, A. Walcarius and K. Vytras, Analysis with Carbon Paste Electrodes, CRS Press, Francis \& Taylor, 2012.

[22] Fritz Scholz (Ed.), Electroanalytical methods: guide to experiments and applications, Springer-Verlag Berlin Heidelberg, 2010. 